Jpn. J. Human Genet. 26, 71-81, 1981

\title{
THE CHANGING SEX RATIO IN JAPAN
}

\author{
Yoko IMAIzUMI $^{1}$ and Motoi Murata ${ }^{2}$ \\ ${ }^{1}$ Institute of Population Problems, Ministry of Health and Welfare, Tokyo 100, Japan, \\ 2 National Institute of Radiological Sciences, Chiba-shi 280, Japan
}

\begin{abstract}
Summary The simultaneous effects of maternal age and birth order on the secondary sex ratio have been examined using data on about 59 million births which occurred in Japan during the period from 1947 to 1978 except 1950. Non-linear negative association between the sex ratio and birth order was observed.

The secondary sex ratio in Japan has been increasing during the period of 1900 through 1978. The change in birth order distribution can explain only a part of the increase in the sex ratio. The decrease in stillbirth rate was not only negatively correlated with the increase in the sex ratio at birth but also with that in fetal deaths. Therefore, it seems that there are some unexplainable factors associated with the increase in the secondary sex ratio other than the decrease in the stillbirth rate. The present results strongly suggest that the true cause of the secular trend in the secondary sex ratio in Japan will be found in the very early stage of pregnancy or at the time of conception.
\end{abstract}

\section{INTRODUCTION}

A large number of factors have been shown to be associated with changes in the secondary sex ratio (see Teitelbaum (1972) for a summary). However, the nature of their effect has never been satisfactorily resolved. Recently Garfinkel and Selvin (1976) and Erickson (1976) have analyzed the effects of paternal age, maternal age, and birth order simultaneously on the sex ratio and have demonstrated a negative association between birth order and the sex ratio. In Japan, Imaizumi and Murata (1979) too have studied the association between the sex ratio, parental age, and birth order simultaneously; birth order exhibited a weak and negative association with sex ratio without statistical significance.

In the present-day Japanese population, the maternal age distribution is more restricted than that seen, for example, in New York City (Imaizumi and Murata, 1979). This diminished variability may be the cause of statistical insignificance in the association between the sex ratio and birth order in Japan. It is of interest, therefore, to study the association between the sex ratio, maternal age and birth

Received August 25, 1980 
order in different time periods. Another purpose of the present paper is to analyze the changing sex ratio at birth and in fetal deaths in Japan.

\section{MATERIALS AND METHODS}

Data on the sex ratio (proportion of males among total births) from 1900 to 1978 were obtained from the vital statistics; information on maternal age and birth order has been given in the statistics from 1947 through 1978 except 1950 . About 59 million births occurred in these years. Birth order is the numerical order of a birth in relation to all children liveborn and prenatally died in the 21 st week of gestation or later. Although data for 1950 are available, birth order was defined in relation to all children liveborn, and thus differs from that for the other years.

The number of classes for each factor is as follows:

\section{No. of classes}

Maternal age class $\quad 7 \quad(<20,20-, 25-, 30-, 35-, 40-$, and $45+)$

Birth order class $\quad 6 \quad(1 \mathrm{st}, 2 \mathrm{nd}, 3 \mathrm{rd}, 4 \mathrm{th}, 5$ th, and 6 th or more)

Multiple regression analysis was used to estimate the parameters of linear and quadratic regression models where maternal age $\left((\mathrm{MA})_{\mathrm{j}}\right)$ and birth order $\left((\mathrm{BO})_{\mathrm{j}}\right)$ were the independent variables and the sex ratio $\left(P_{i j}\right)$ was the dependent one. The parameters of the linear regression model (i.e. $\left.\mathrm{P}_{\mathrm{ij}}=\mathrm{b}_{0}+b_{1}(\mathrm{MA})_{\mathrm{i}}+\mathrm{b}_{2}(\mathrm{BO})_{\mathrm{j}}\right)$ were estimated by the least squares method using weights

$$
\hat{w}_{i j}=\frac{n_{i j}}{\hat{p}(1-\hat{p})}
$$

where $n_{i j}$ is the number of births within a specific maternal age-birth order category and $\hat{\mathrm{p}}$ is the overall sex ratio.

The quadratic model (Novitski and Kimball, 1958) was as follows:

$$
P_{i j}=b_{0}+b_{1}(M A)_{i}+b_{2}(B O)_{j}+b_{11}(M A)_{i}{ }^{2}+b_{22}(B O)_{j}{ }^{2}+b_{12}(M A)_{i}(B O)_{j} .
$$

As will be shown in the next section, the sex ratio in 1966 through 1971 is unusually high, which may be due to some artificial factors during the data processing. Therefore, the data were divided into three time periods, namely, 1947-1965, 1966-1971, 1972-1978. Both regression models were fitted to the 42 observed age-birth order sex ratios in individual year groupings as well as to the pooled data.

\section{RESULTS}

Secondary sex ratio

In Figure 1 changes in the mean sex ratio in successive years since 1900 are shown. It is evident that the sex ratio has gradually increased with time. The 


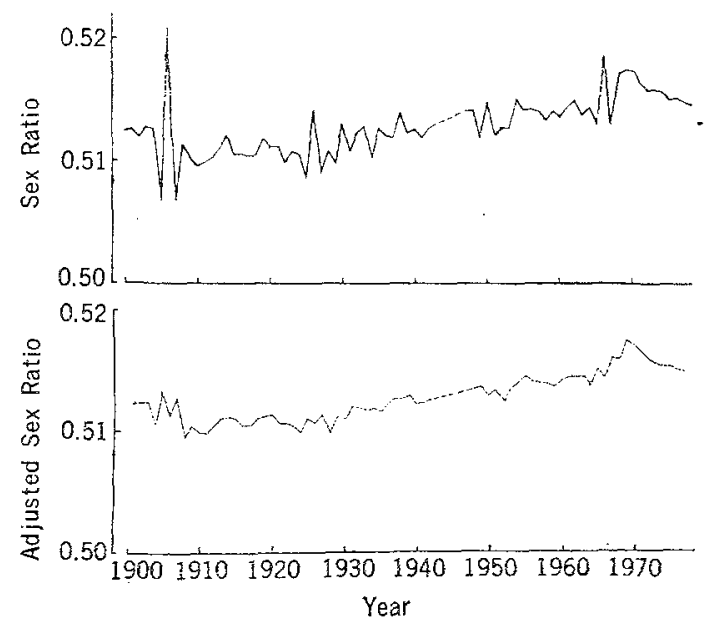

Fig. 1. Yearly change in the secondary sex ratio and the 3 -point average of the sex ratio in Japan.

regression coefficient of the secondary sex ratio on year from 1900 to 1978 is $0.00006885 \pm 0.00000948$ which is significant at the $1 \%$ level. Other fluctuations are considered to be stochastic in nature, excepting the large ones around 1906 and 1966. These years correspond to Hinoe-Uma in the ancient Japanese calendar an unpropitious sign for female babies. Many Japanese people are reluctant to give birth to a female baby in these years. Accordingly some girls born early in the year of Hinoe-Uma were undoubtedly registered as born at the end of the previous year, and those born at the end of the year registered as born at the beginning of the next year. To minimize the effect of the years of Hinoe-Uma, smoothing techniques were applied to compute the sex ratio; the average of three adjacent data points weighted by the sample sizes for the raw data points were used. Figure 1 also shows the 3-point smoothed data curve for the period from 1901 to 1977. A gradual upward trend in the sex ratio from 1908 to 1964 will be noted. In the smoothed data, the regression coefficient of sex ratio on year for the period 1901 to 1977 is $0.0000715 \pm 0.0000051$, a value significant at the $1 \%$ level.

To study the association between sex ratio, maternal age and birth order, data on the sex ratio were used for the period from 1947 to 1978 except 1950 . According to Fig. 1, the sex ratio gradually increased from 1947 to 1965 , increased rapidly in the period of 1966 through 1970 and returned to the ordinary level in 1972 . Thus, these data are grouped into three classes: the periods 1947 to 1965 except 1950 , 1966 to 1971 and 1972 to 1978 (Table 1). The association of the sex ratio with maternal age or birth order varies considerably in these three periods, as is shown in Figs. 2 and 3. In the case of the linear model, the squares of the multiple correlation coefficients, $\mathrm{R}^{2}$, were $0.034,0.155,0.008$ for the first, second and third chronological periods, respectively. The signs of the regression coefficients were not 


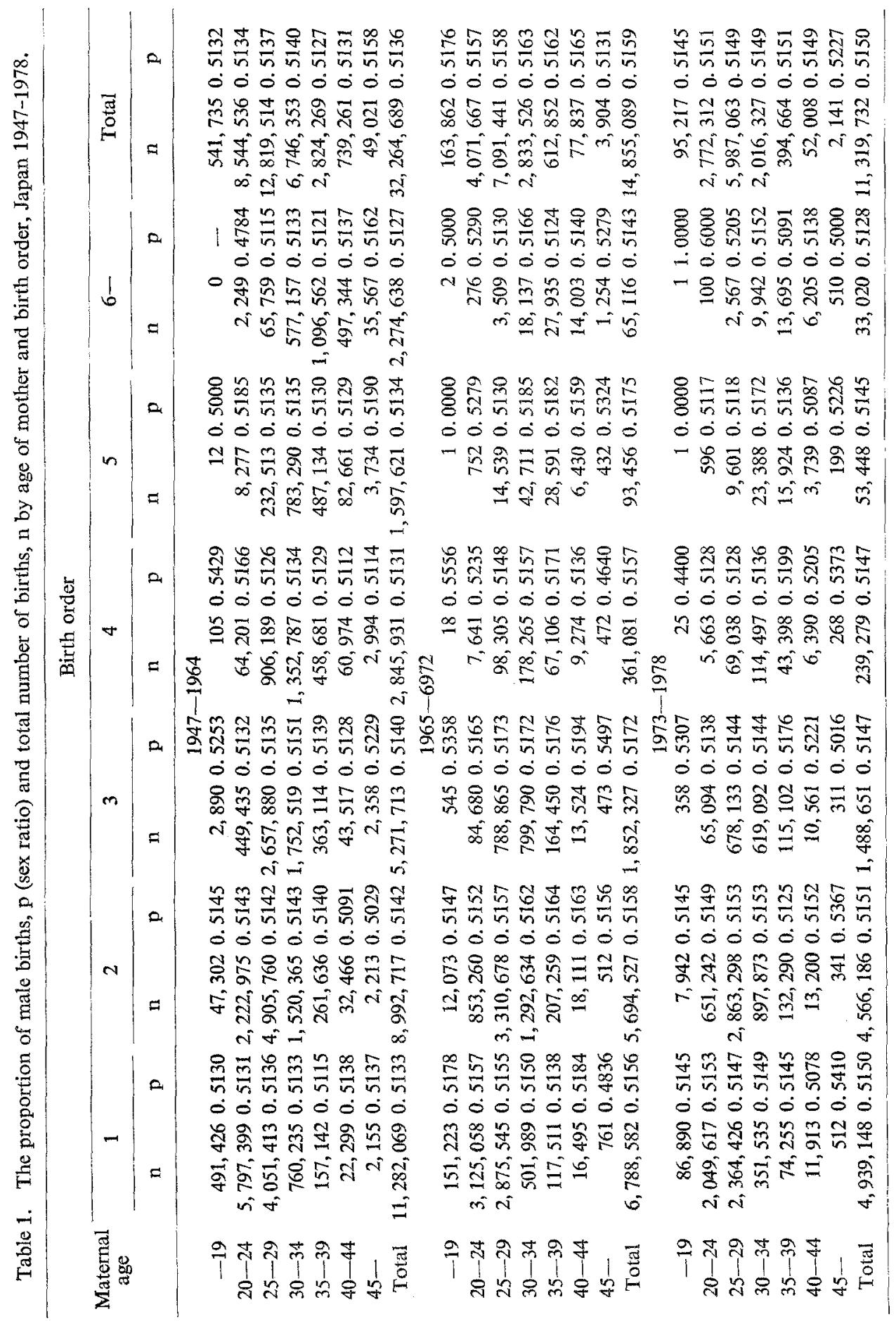




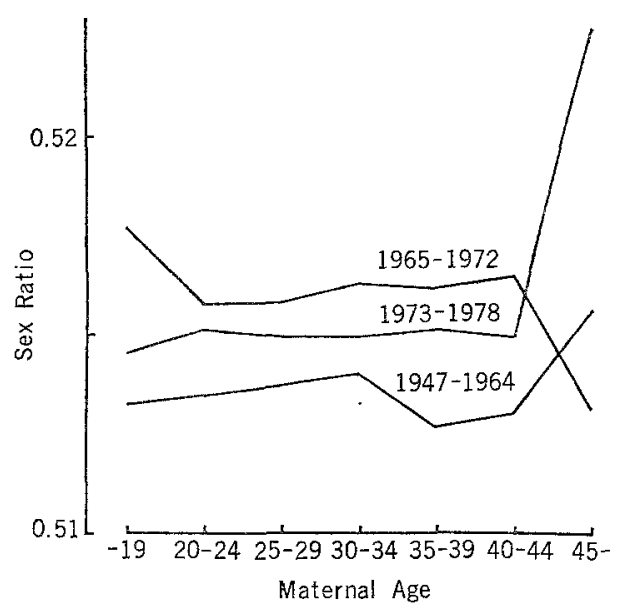

Fig. 2. Sex ratio and maternal age.

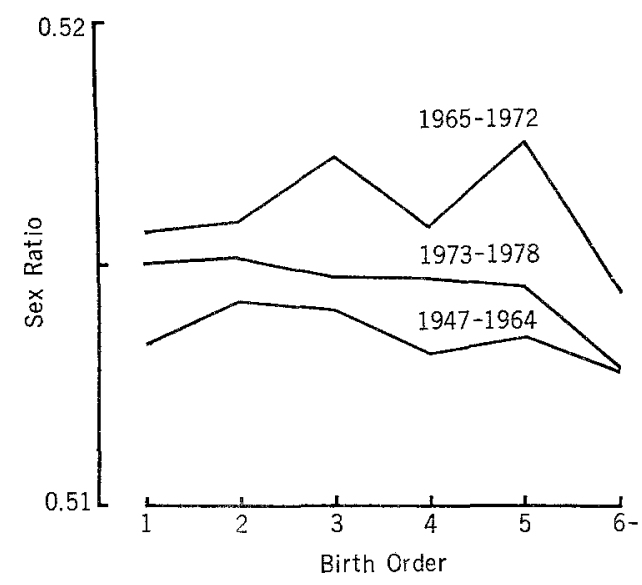

Fig. 3. Sex ratio and birth order.

consistent among these three groups. In Table 2 the results of the multiple regression analysis with the quadratic model are given for these three groups. The $R^{2} \mathrm{~S}$ differ from those associated with the linear model. A negative partial regression coefficient on the quadratic term of birth order was obtained in all groups; however, only the value for the second group was not significant at the $5 \%$ level. A positive partial regression coefficient on the interaction term of maternal age and birth order was obtained in all groups; only the value for the third group was significant.

When the data (from 1947 to 1978 omitting 1950) are pooled, independent effects of year, maternal age and birth order can be tested with three variables multiple regression analysis (Table 3). With the linear model, only the effect of year is significant. With the quadratic model, the effect of year can be decomposed 
Table 2. Multiple regression analysis of the effect of maternal age and birth order on the sex ratio in successive years with a quadratic model.

\begin{tabular}{ccrrrrr}
\hline Year & $R^{2}$ & \multicolumn{5}{c}{ Regression coefficients and standard errors $\left(\times 10^{2}\right)$} \\
\cline { 3 - 6 } & & \multicolumn{1}{c}{$b_{M A}$} & \multicolumn{1}{c}{$b_{\text {BO }}$} & $b_{M A}{ }^{2}$ & $b_{B O}{ }^{2}$ & $b_{M A \times B O}$ \\
\hline $1947-1964$ & 0.292 & $0.683 \pm 0.642$ & $0.593 \pm 0.406$ & $-0.139 \pm 0.120$ & $-0.207 \pm 0.070^{*}$ & $0.157 \pm 0.135$ \\
$1965-1972$ & 0.245 & $-0.776 \pm 0.820$ & $0.650 \pm 0.648$ & $0.042 \pm 0.142$ & $-0.251 \pm 0.129$ & $0.270 \pm 0.215$ \\
$1973-1978$ & 0.142 & $-0.512 \pm 0.933$ & $-0.368 \pm 0.747$ & $-0.060 \pm 0.161$ & $-0.315 \pm 0.150^{*}$ & $0.499 \pm 0.246^{*}$
\end{tabular}

* Significant at $5 \%$ level.

Table 3. Multiple regression analysis on the effects of year, maternal age and birth order on the sex ratio with linear and quadratic models, 1947-1978.

\begin{tabular}{|c|c|c|c|c|c|c|}
\hline \multirow{2}{*}{ Model } & \multirow{2}{*}{$\mathrm{R}^{2}$} & \multicolumn{5}{|c|}{ Regression coefficients $\times 10^{3}$ (S.E. $\times 10^{3}$ ) } \\
\hline & & byr & $\mathrm{b}_{\mathrm{MA}}$ & $b_{B O}$ & $b_{Y R_{0}}^{2}$ & $b_{M . A}^{2}$ \\
\hline$(\mathrm{YR}, \mathrm{MA}, \mathrm{BO})$ & 0.090 & $\begin{array}{l}0.095 * * \\
(0.009)\end{array}$ & $\begin{array}{c}0.053 \\
(0.108)\end{array}$ & $\begin{array}{c}-0.008 \\
(0.084)\end{array}$ & & \\
\hline$(\mathrm{YR}, \mathrm{MA}, \mathrm{BO})^{2}$ & 0.105 & $\begin{array}{c}0.152^{* *} \\
(0.048)\end{array}$ & $\begin{array}{r}-0.044 \\
(0.531) \\
\end{array}$ & $\begin{array}{r}0.606 \\
(0.387) \\
\end{array}$ & $\begin{array}{r}-0.002 * \\
(0.001) \\
\end{array}$ & $\begin{array}{c}-0.066 \\
(0.089) \\
\end{array}$ \\
\hline \multirow{2}{*}{ Model } & \multirow{2}{*}{$\mathrm{R}^{2}$} & \multicolumn{5}{|c|}{ Regression coefficients $\times 10^{3}$ (S.E. $\left.\times 10^{3}\right)$} \\
\hline & & $\mathrm{b}_{\mathrm{BO}}^{2}$ & \multicolumn{2}{|c|}{$b_{Y R \times M A}$} & $\mathrm{~b}_{\mathrm{YR} \times \mathrm{BO}}$ & $\mathrm{b}_{\mathrm{MA}} \times \mathrm{BO}$ \\
\hline$(\mathrm{YR}, \mathrm{MA}, \mathrm{BO})$ & 0.090 & & & & & \\
\hline$(\mathrm{YR}, \mathrm{MA}, \mathrm{BO})^{2}$ & 0.105 & $\begin{array}{c}-0.213^{* * *} \\
(0.061)\end{array}$ & \multicolumn{2}{|c|}{$\begin{array}{c}0.007 \\
(0.012)\end{array}$} & $\begin{array}{c}-0.004 \\
(0.010)\end{array}$ & $\begin{array}{c}0.195 \\
(0.109)\end{array}$ \\
\hline
\end{tabular}

* Significant at the $5 \%$ level. ** Significant at the $1 \%$ level.

into the positive linear and negative quadratic terms, both of which are statistically significant. In addition the effect of birth order quadratic term is negatively associated with the sex ratio. Positive effect of maternal age-birth order interaction is also seen, though not statistically significant.

\section{Sex ratio in fetal and early neonatal deaths}

The sex ratio in fetal deaths was computed using the vital statistics since 1900 (Fig. 4). This sex ratio too has gradually increased with time; the regression coefficient on year is $0.00069 \pm 0.00002$ which is significant at the $1 \%$ level. Fetal deaths have been separated into spontaneous and artificial stillbirths since 1947. The sex ratio in spontaneous stillbirths gradually increased with year whereas the sex ratio in artificial stillbirths decreased with year until 1960 and increased thereafter (Fig. 4).

The sex ratio by month of gestation was obtained since 1950 (Fig. 5). According to these data, the sex ratio in spontaneous and artificial stilibirths for 3 completed months of gestation decreased with year until 1960 and increased thereafter. 


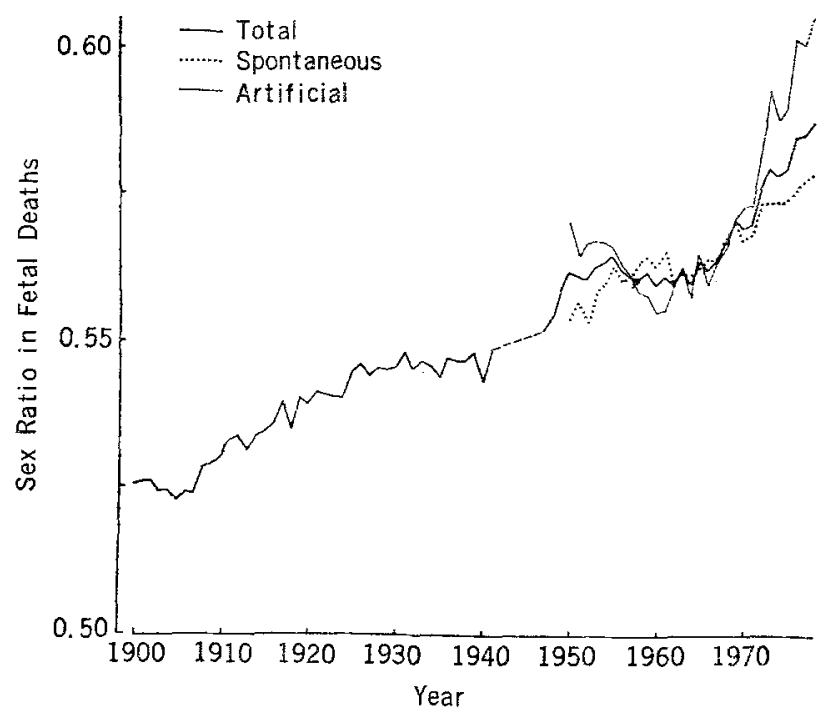

Fig. 4. Yearly change in the sex ratio in fetal deaths.

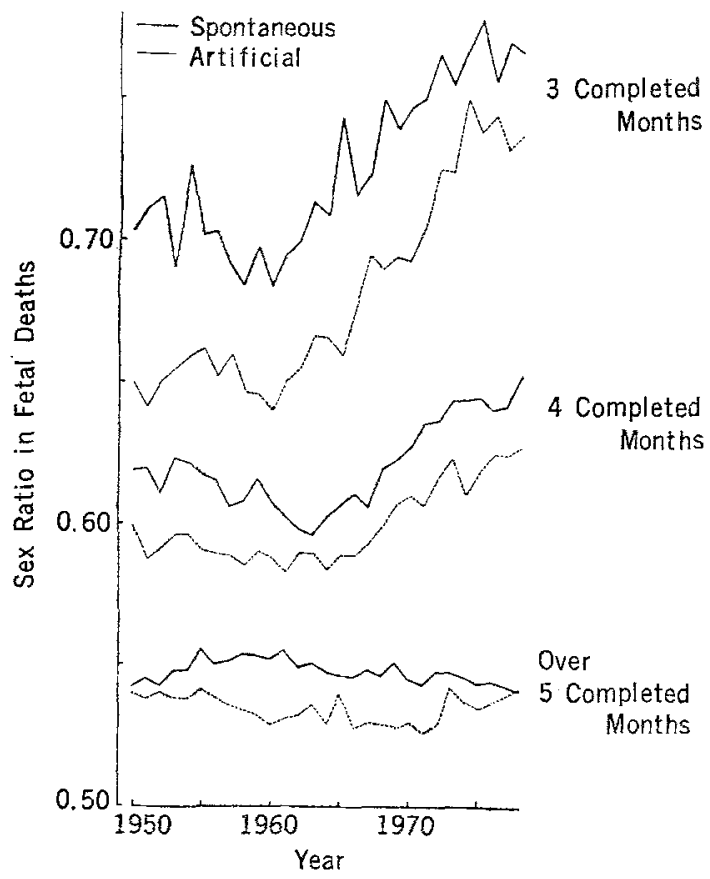

Fig. 5. Sex ratio in fetal deaths according to month of gestation, 1950-1978.

Vol. 26, No. 2, 1981 
Nearly the same trend was observed in the case of 4 completed months of gestation. However, the sex ratios in spontaneous and artificial stillbirths remained almost constant in the case of over 5 completed months of gestation.

\section{DISCUSSION}

In spite of many studies of the factors associated with the sex ratio as previously mentioned, few longitudinal studies of the sex ratio at birth exist. Pollard (1969) studied the sex radio in Australia, 1902-1965, McMahan (1951) in the United States, 1915-1948, and Seki (1968) in England and Wales, 1900-1965, and in France, 1900-1964, respectively. The regression coefficients of the sex ratio on year in Australia during the period from 1902 to 1976 (Sources: Pollard, 1969; Official Year Book of The Commonwealth of Australia, 1969; Births, 1976) and in France during the period from 1900 to 1964 are $0.000009 \pm 0.000008$ and $0.000018 \pm$ 0.000010 , respectively, neither of which is statistically significant, whereas the regression coefficients of the sex ratio on year in the United States for whites and Negroes during 1915 through 1975 and in England and Wales during the period from 1900 to 1965 are $-0.000013 \pm 0.000004,-0.000027 \pm 0.000013$ (Sources: McMahan, 1951; Vital Statistics of The United States, 1973; Monthly Vital Statistics Report, 1976), and $0.000101 \pm 0.000007$, respectively. These values are significant at the $1 \%, 5 \%$, and $1 \%$ levels, respectively. Thus, despite the decrease in the stillbirth rate throughout the world during the 20th century, a consistent secular change in the sex ratio at birth has not been observed. There has been an increase in Japan and England and Wales, a decrease in the United States for whites and Negroes, and no change in Australia and France.

The present results demonstrate that the secondary sex ratio in Japan has been increasing during the past seven decades. However much short term variation has existed (Fig. 1), of which the effect of the year of Hinoe-Uma is the most striking. The other is the unusually high values in the period from 1966 to 1971 . The mean sex ratios at birth for the periods from 1947 to 1965 , from 1966 to 1971 and from 1972 to 1978 are $0.5136,0.5159$ and 0.5151 . We suspect that the computerized data analysis introduced in 1968 by the Health and Welfare Information Department of the Ministry of Health and Welfare may have brought about the higher sex ratio seen in the years 1968 to 1970 inclusive. When we code 1 for males and 2 for females, a mispunch of a 1 for 2 is more probable than a 2 for a 1 . This could be the cause of the raised sex ratio during these years. The sex ratio after 1971 returned toward the ordinary level. Even after excluding the data of 1966 through 1971, the positive regression on year remains statistically significant.

What are the causes of the increase in the secondary sex ratio in Japan? A suspected reason for this change is the shift in the distribution of births by age of father, age of mother or birth order. Almost all studies on sex ratio at birth, including the Japanese data, indicate a negative association with birth order (Imai- 
zumi and Murata, 1979). In Japan, the proportion of births of order 4 and over was $28.4 \%$ in 1950 , and gradually decreased to $2.7 \%$ in 1978 . Roughly speaking, the sex ratio could be expected to decrease by at most 0.004 or more probably 0.002 in the births as late as the 4th or more, which is computed using the regression coefficients, $b_{\mathrm{BO}}$ and $\mathrm{b}_{\mathrm{BO}}^{2}$ in Table 3 . Thus the loss of $25 \%$ of these later births would result in an increase of approximately 0.0005 in the sex ratio. However, the actual increment observed during the 27 years after 1950 is 0.002 . Thus, the change in birth order distribution can explain only a part of the increase in the sex ratio.

Seki (1968) and Matsuyama (1972) pointed out an increase in the sex ratio at birth using vital statistics for the period from 1900 to 1959 or 1900 to 1972 in Japan, respectively. The former author did not confirm that the decrease in stillbirth rate caused the increase in sex ratio at birth. But, the latter author, Matsuyama, mentioned that the recent decrease in the stillbirth rate suggests a possible relation with the increase in the sex ratio at birth. In the present study, the correlation coefficients between the sex ratio in fetal deaths and the stillbirth rate for spontaneous and artificial stillbirths for the period from 1950 to 1978 are individually -0.65 and -0.80 , and are statistically significant at the $1 \%$ and $0.1 \%$ level, respectively. The correlation coefficient between the sex ratio at birth and the stillbirth rate (only spontaneous stillbirth rate after 1948 and the rates for 1948 to 1949 are based on round numbers) is -0.44 for the period from 1900 to 1978 except the years 1944 to 1946 inclusive, which is statistically significant at the $0.1 \%$ level. Therefore, the decrease in stillbirth rate was not only negatively correlated with the increase in the sex ratio at birth but also with that in fetal deaths. The correlation coefficient between the sex ratio in early neonatal deaths and early neonatal mortality is -0.93 (significant at the $0.1 \%$ level) (Fig. 6). Therefore, it seems that there are some unexplainable factors associated with the increase in the secondary sex ratio other than the decrease in the stillbirth rate.

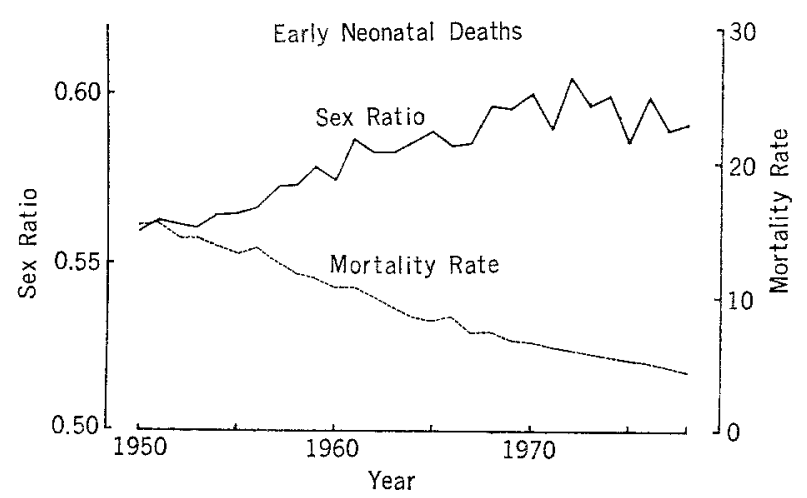

Fig. 6. Yearly change in the sex ratio in early neonatal deaths and early neonatal mortality, 1950-1978. 
Teitelbaum (1971) concluded that decreases in the sex ratio of late fetal deaths are associated with increases in the sex ratio of early infant deaths. Recently McMillen (1979) has analyzed the sex ratio in fetal and neonatal deaths using vital statistics data for the United States from 1922 to 1936 and from 1950 to 1972 . His results support Teitelbaum's argument that the increase in secondary sex ratio is due to the postponement of late fetal deaths into the early infant period. However, in Japan, the decrease in the sex ratio of late fetal deaths is manifested after 1963, whereas the increase in the sex ratio of early infant deaths is observed since 1950. Thus, Teitelbaum's result is not exactly confirmed by the Japanese data. Furthermore the sex ratio in early fetal deaths itself is increased in these years.

The results presented here suggest that the primary sex ratio itself may have been raised, or alternatively that very early fetal deaths may have been reduced more for males than females. It is almost impossible to know the primary sex ratio in human material. Even the data on sex ratio in very early stage of gestation are not available in the vital statistics. With recent reports, however, it has been clarified that the sex ratio in very early stages of development is not so high as previously believed. Yamamoto et al. (1977) obtained 516 males in a total of 1,000 induced abortions (average gestational age $8.4 \pm 1.5$ weeks) with sex chromosome testing. Although their sample size is small, it suggests that the sex ratio among early stillbirths in the vital statistics overestimate the real value because of some biases in identifying sexes. Notwithstanding this unreliableness, the steep rise in the sex ratio in stillbirths of 3 completed months of gestation during the past 20 or more years (Fig. 5) can not be ignored. It strongly suggests that the true cause of the secular trend in the secondary sex ratio in Japan will be found in the very early stage of pregnancy or at the time of conception.

Acknowledgements We are indebted to Dr. W.J. Schull of Radiation Effects Research Foundation, Hiroshima for reading the manuscript and correcting the English.

\section{REFERENCES}

Australia, Commonwealth Bureau of Census and Statistics 1969 Oficial Year Book of The Commonwealth of Australia, No. 55, Commonwealth Bureau of Census and Statistics, Canberra.

Australia, Bureau of Statistics 1976 Births, Catalogue No. 3301. Australian Bureau of Statistics, Canberra.

Erickson, J.D. 1976. The secondary sex ratio in the United States 1969-1971: Association with race, parental ages, birth order, paternal education and legitimacy. Ann. Hum. Genet. 40: 205-212.

Garfinkel, J. and Selvin, S. 1976. A multivariate analysis of the relationship between parental age and birth order and the human secondary sex ratio. J. Biosoc. Sci. 8: 113-121.

Imaizumi, Y. and Murata, M. 1979. The secondary sex ratio, paternal age, maternal age, and birth order in Japan. Ann. Hum. Genet. 42: 457-465.

Japan, Ministry of Health and Welfare. (1949-1951 and 1953-1978) Vital Statistics 1947-1951 and 1953-1978. Vol. 1. Health and Welfare Statistics Division, Minister's Secretariat, Tokyo. 
Matsuyama, T. 1972. The recent increase in the sex ratio at birth and related factors in Japan. Human Ecol. and Race Hygiene (in Japanese) 38: 61-67.

McMahan, C.A. 1951. An empirical test of three hypotheses concerning the human sex ratio at birth in the United States, 1915-1948. The Milbank Memorial Found Quarterly 29: 273-293.

McMilien, M.M. 1979. Differential mortality by sex in fetal and neonatal deaths. Science 204: 89-91.

Monthly Vital Statistics Report 1976 Advance Report Final Natality Statistics. 1975. The National Center for Health Statistics. Vol. 25, No. 10. Supplement.

Novitski, E. and Kimball, A.W. 1958. Birth order, parental ages, and sex of offspring. Am.J. Human Genet. 10: 268-275.

Pollard, G.N. 1969. Factors influencing the sex ratio at birth in Australia, 1902-1965, J. Biosoc. Sci. 1: $125-144$.

Seki, Y. 1968. Increase in the sex ratio at birth in Japan. The Ritsumeikan Economic Review (in Japanese) 17: 381-412.

Teitelbaum, M.S. 1971. Male and female components of perinatal mortality: International trends, 1901-63. Demography 8: 541-548.

Teitelbaum, M.S. 1972. Factors associated with the sex ratio in human populations. The Structure of Human Populations (G.A. Harrison and A.J. Boyce, eds.), Clarendon Press, Oxford, pp. 90-109.

U.S. Department of Health, Education, and Welfare 1973 Vital Statistics of The United States. Vol. 1-Natality. Department of Health, Education, and Welfare.

Yamamoto, M., Ito, T., and Watanabe, G. 1977. Determination of prenatal sex ratio in man. Human Genet. 36: 265-269. 